doi:10.17659/01.2019.0012

Journal of Case Reports 2019;9(1):44-46

\title{
Primary Small Cell Neuroendocrine Tumor of Breast: A Mammary Gland Enigma
}

\author{
Aniket Sharma, Rohit Mehra, Gursewak Singh, AK Tyagi \\ Department of Surgery, Armed Forces Medical College, Pune 411040, Maharashtra, India.
}

\section{Corresponding Author:}

Dr. Rohit Mehra

Email: capocrimini.rohit@gmail.com

This is an Open Access article distributed under the terms of the Creative Commons Attribution License (creativecommons.org/ licenses/by/3.0).

Received Accepted Published

November 5, 2018

February 14, 2019

March 5, 2019

\begin{abstract}
Background: Primary small cell neuroendocrine tumor of the breast is a rare form of tumor with very few reported cases in the medical literature. The rarity of the disease has produced a lacuna in the management algorithms of the disease. Most of the times extrapolation of management protocols of small cell carcinoma lung is employed. Case Report: We report here a primary small cell neuroendocrine tumor of the breast in a post-menopausal lady. The diagnosis was reached by DOTA-NOC scan, considered highly specific for neuroendocrine tumors and post-operative histopathological examination. Conclusion: Breast is an extremely rare site for primary small cell carcinoma. Management protocols in existence are yet to be standardized.
\end{abstract}

Keywords: Breast, Neuroendocrine Tumor, Radionuclide Imaging, Small Cell Carcinoma.

\section{Introduction}

Breast cancer is the leading cause of cancerrelated death in women. With an incidence of $<1 \%$, primary small cell neuroendocrine tumors (PSCNET) of breast, are a rare entity, amongst all breast malignancies [1,2]. First described in 1983 , by Wade et al., there are fewer than hundred cases reported in medical literature [3]. They share morphological similarity with the neuroendocrine tumors (NET) of gastrointestinal system and the lung. However, due to the rarity of the condition, there is a peculiar lacuna in the surgical principles and management protocols for primary PSCNET of the breast, despite the fact that they are poorly differentiated and have a higher tumor nuclear grade, carrying a poor prognosis [4]. We present one such case of a primary small cell neuroendocrine breast cancer.

\section{Case Report}

A 66-year-old, post-menopausal lady, known hypertensive, presented with a non-tender lump in the left breast, of two months duration. She had no associated nipple discharge, retraction of nipples, redness of the overlying skin or ulceration over the breast. There was no history of any axillary swelling or similar lump in the contralateral breast. Clinically, she had a performance status of 0 (ECOG), with normal hematological and biochemical findings. The lump was $5 \times 6 \mathrm{~cm}$ (cT3), mobile with few non-tender, non-matted ipsilateral axillary lymph nodes (cN1). There was no evidence of metastasis on examination and imaging.

Mammographically, a lesion measuring $43.7 \times 23.5 \times 33.6 \mathrm{~mm}$ at 6 to $7 \mathrm{o}$ ' clock position, $2 \mathrm{~cm}$ from left nipple-areola complex, with no echogenic contents/calcifications/increased vascularity, but with few ipsilateral axillary lymph nodes, was noted. A core-cut biopsy revealed a high-grade primary neuroendocrine tumor (NET) with triple negativity (estrogen receptor, progesterone receptor and HER-2neu negative status) and triggered immunohistochemical staining for synaptophysin and chromogranin [Fig.1]. A 3.3 mCi-Ga-68 
DOTA-NOC scan, considered highly specific for neuroendocrine tumors, as they universally express somatostatin receptors, revealed $52 \times 26 \mathrm{~mm}$ left breast lesion, with avid tracer uptake with no other body lesion [Fig.2].

The goals of treatment were discussed with the patient and decision of upfront surgery was offered. She underwent modified radical mastectomy of the left breast [Fig.3]. The postoperative period was uneventful. Histopathological report revealed a PSCNET of the left breast, with lymphovascular and perineural invasion. Microscopically, the tumor was characterized by atypical cells organized in solid and trabecular arrangements, with high nuclear:cytoplasmic ratio, pleomorphic heterochromatic dimorphic nuclei with inconspicuous nucleoli and scant cytoplasm. The tumor cells were highly positive for neuron specific enolase (NSE), chromogranin and synaptophysin and negative for c-erb-B2 and cytokeratin 20 [Fig.3]. Five out of the 30 lymph nodes dissected from the left axilla were positive with metastatic tumor deposits. This lymphovascular and perineural invasion was managed with chemotherapy, doxorubicin $60 \mathrm{mg} / \mathrm{m}^{2}$ and cyclophosphamide $600 \mathrm{mg} / \mathrm{m}^{2}$ (AC), in four cycles every 21 days, followed by carboplatin $300 \mathrm{mg} / \mathrm{m}^{2}$ during day one and etoposide $120 \mathrm{mg} / \mathrm{m}^{2}$ during days one to three, (CE) for three cycles every 28 days. The choice of drugs was made on basis of their described efficacy in small cell carcinoma of lung and breast carcinoma. At the time of writing the patient is 10 months out of her diagnosis and is disease free.

\section{Discussion}

Primary small cell neuro-endocrine tumors of the breast are rare tumors. Earlier hypotheses suggested they are derived from migrated neural crest cells while the recent hypothesis expounds on divergent differentiation of neoplastic stem cells $[5,6]$. There elusive presence in the medical literature has for long kept this entity from being thoroughly researched and catalogued with

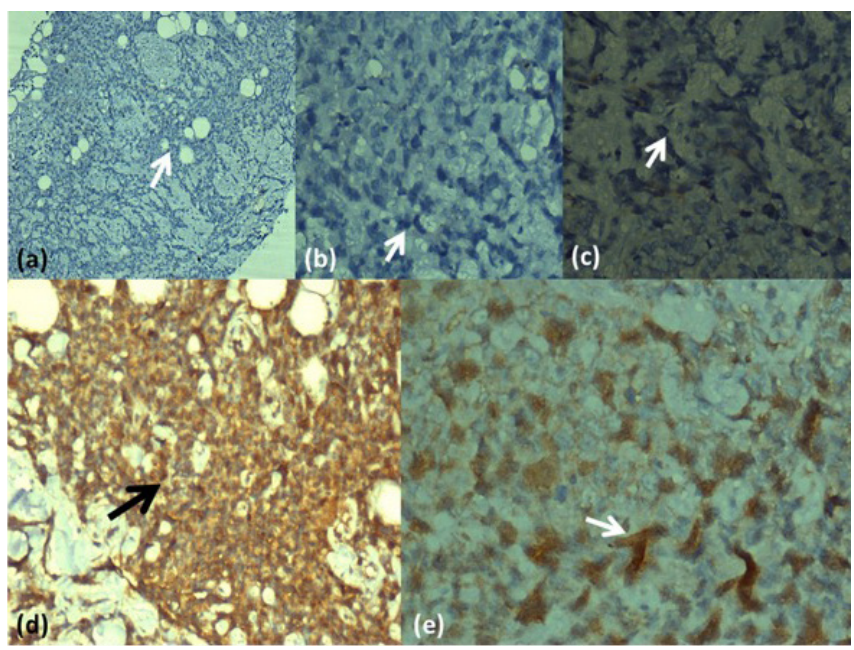

Fig.1: Neuroendocrine cells staining negative for (a) Progesterone receptors (PR); (b) Estrogen receptors (ER); (c) HER-2 neu receptors. Neuroendocrine cells showing staining with (d) chromogranin and (e) synaptophysin (100x).

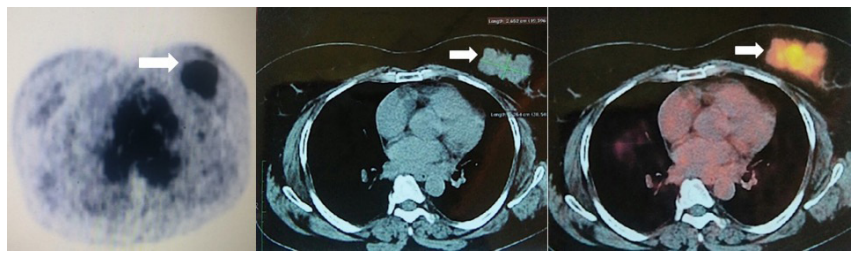

Fig.2: Ga-68 DOTATATE PET/CT scan showing a SSTRexpressing lesion on MIP images in the left breast, of approximately $43.7 \times 23 \times 3.5 \times 33.6 \mathrm{~mm}$.

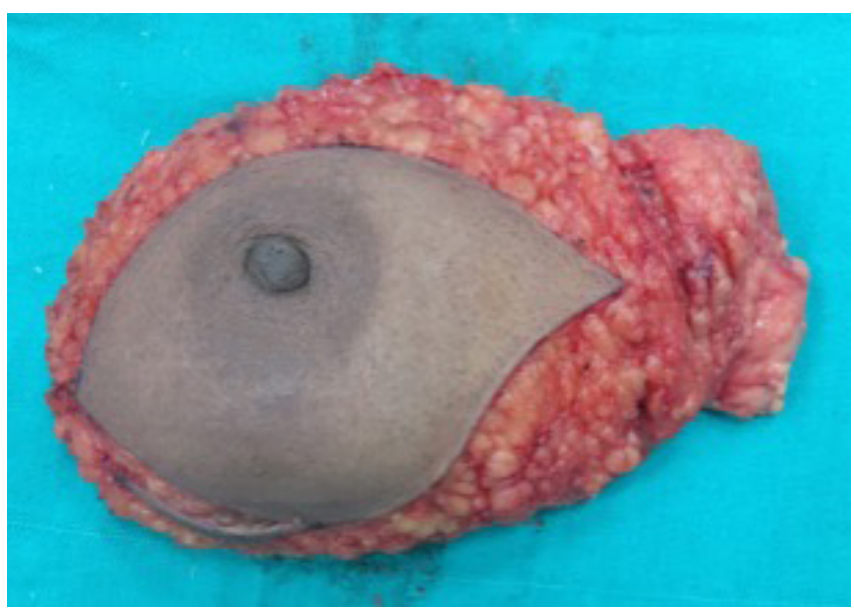

Fig.3: Post-operative specimen of modified radical mastectomy left breast. 
oncological pragmatism. Most of the suggested treatment comprises of breast conservation surgery or modified radical mastectomy with adjuvant chemotherapy, with no proven role of radiotherapy $[6,7]$.

Histologically, as late as 2003, World Health Organization adopted Sapino et al.'s three histological subtypes of NET of breast, namely, well differentiated tumors; poorly differentiated tumors (includes PSCNET breast) and invasive tumors with neuroendocrine features, as an official pathological category $[8,9]$. The diagnosis of primary neuroendocrine tumor of the breast is considered if more than $50 \%$ of the tissue under examination, shows neuroendocrine markers with coexisting intra-ductal component and exclusion of extra-mammary sites has been achieved by targeted imaging [8].

Mastectomy has been advocated as the firstline treatment due to the aggressive nature of the disease. Of-late, proponents of breast-conserving surgery with chemotherapy has also tried to formulate evidence-based treatment algorithms, but the rare nature of the disease renders them anecdotal. A few case reports on the subject describe use of chemotherapy regimens, utilized in both small cell neuroendocrine tumor lung and invasive breast tumors. Platinum based chemotherapy is although used for PSCNET of breast, as it shares the common biological markers with small cell carcinoma lung. There exists a biochemical analogy between granin and BRCA protein, hence chromogranin presence in NET breast might hold promise in future targeted therapy against the disease. Novel therapeutic regimes particularly involving anti-angiogenesis agents are underway. It is high time that a well-researched, objectively proven guidelines for treatment of this rare entity is placed on record. Yet the best management algorithm is still an enigma and prognosis for PSCNET breast is not established $[1,10]$.

\section{Conclusion}

PSCNET of breast is a rare tumor and unlike the lobular and ductal carcinomas of the breast, there are no well-defined algorithms in place for this atypical breast cancer. Despite the lack of randomized control trials, the extrapolation of management of small cell carcinoma lung to this disease shows promising results. There is a need for extensive research in the field of PSCNET of breast, owing to its rare presence, to redefine the conventional prognostic and therapeutic parameters and strengthen the existing treatment algorithms.

Contributors: AS: manuscript writing, patient management; RM, GS: manuscript editing, patient management; AKT: critical inputs into the manuscript. RM will act as guarantor. All authors approved the final version of this manuscript. Funding: None; Competing interests: None stated.

\section{References}

1. AbouDalle I, Abbas J, Boulos F, Salem Z, Assi HI. Primary small cell carcinoma of the breast: a case report. Med Case Rep. 2017;11:290-294.

2. Zhu Y, Li Q, Gao J, He Z, Sun R, Shen G, et al. Clinical features and treatment response of solid neuroendocrine breast carcinoma to adjuvant chemotherapy and endocrine therapy. Breast J. 2013;19:382-387.

3. Bonel CA, Carretero-González A, Salamanca J, Murillo MT, Manso ML, Tomás Pascual T. A case of a primary small-cell neuroendocrine carcinoma of the breast. Canc Therapy \& Oncol Int. J 2017;7(1): CTOIJ. MS.ID.555701.

4. Bigotti G, Coli A, Butti A, del Vecchio M, Tartaglione R, Massi G. Primary small cell neuroendocrine carcinoma of the breast. J Exp Clin Cancer Res. 2004;23:691-696.

5. Bussolati G, Gugliotta P, Sapino A, Eusebi V, Lloyd RV. Chromogranin-reactive endocrine cells in argyrophilic carcinomas ("carcinoids") and normal tissue of the breast. Am J Pathol. 1985;120:186-192.

6. Adams RW, Dyson P, Barthelmes L. Neuroendocrine breast tumours: breast cancer or neuroendocrine cancer presenting in the breast? Breast. 2014;23:120-127.

7. Yildirim Y, Elagoz S, Koyuncu A, Aydin C, Karadayi $\mathrm{K}$. Management of neuroendocrine carcinomas of the breast: A rare entity. Oncol Lett. 2011;2:887-890.

8. Tan PH, Schnitt SJ, van de Vijver MJ, Ellis IO, Lakhani SR. Papillary and neuroendocrine breast lesions: the WHO stance. Histopathology. 2015;66:761-770.

9. Sapino A, Papotti M, Righi L, Cassoni P, Chiusa L, Bussolati G. Clinical significance of neuroendocrine tumors of breast. Ann Oncol. 2001;12;115-117.

10. Watrowski R, Jäger C, Mattern D, Horst C. Neuroendocrine carcinoma of the breast-diagnostic and clinical implications. Anticancer Res. 2012;32:50795082 . 